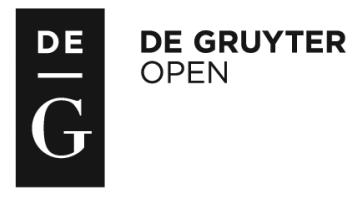

Administration, vol. 64, no. 2 (2016), pp. 85-108

doi: 10.1515/admin-2016-0017

\title{
Governance of the table: Regulation of food and eating practices in residential care for young people
}

\author{
Deirdre Byrne \\ Independent researcher
}

\begin{abstract}
This paper explores how food and eating practices are governed in residential care for young people and who or what governs the table in residential care centres. The governance of everyday food and eating practices in residential care is multifaceted and conducted on multiple levels by external and internal authority and regulation. This paper draws on Coveney's 2008 theory on 'the government of the table' that builds on the Foucauldian perspective of governmentality to explore the interplay between internal and external regulation, which in turn highlights the tensions between institutional and homely aspects of residential care. The approach taken involves an exploratory, sequential mixed-methods design of focused ethnography in five centres, a survey of ninety-two social care practitioners working in the field and a review of Health Information and Quality Authority inspection reports.
\end{abstract}

Keywords: Residential care, children, food, governance, home 


\section{Introduction}

Food is central to our everyday lives. It 'is packed with social, cultural and symbolic meaning' (Bell \& Valentine, 1997, p. 3), but its significance can often be overlooked. Food is used symbolically and practically to demonstrate both care and control in residential care (Emond et al., 2013; McIntosh et al., 2010; Punch et al., 2009). At the same time, food practices in residential care are 'mundane and everyday activities' and, as such, the 'symbolic significance can be easily overlooked' (Punch et al., 2009, p. 13).

In Ireland we know little about how young people in residential care are fed despite the relationship between children and food being high on the political agenda. Of particular concern is childhood obesity, and Safefood, in partnership with the Health Service Executive (HSE), maintains that there is a growing trend towards obesity, physical inactivity and unhealthy eating habits in Ireland (Safefood, 2011). Wright et al. (2012, p. 673) argue that current campaigns and policy are designed and directed towards young people 'who are a risk to themselves and the state because of their ungoverned/unruly behaviour and bodies'. Workers in residential care are responsible for providing food for the children in their care and therefore must interpret (and sometimes challenge) policy, regulation and health campaigns with a nutritionist-driven approach that largely sees feeding children as simply providing healthy food.

This paper explores the governance of everyday food and eating practices in residential care centres for young people. Using an exploratory, sequential mixed-methods design of focused ethnography in five centres, a survey of ninety-two social care practitioners working in the field and a review of Health Information and Quality Authority (HIQA) inspection reports, this paper considers how food regulation works and who or what 'governs the table' in residential care.

According to Clark et al. (2014, p. 4), residential care centres can be clearly characterised as 'a workplace for staff, a temporary home for residents' that is 'governed by externally and internally generated institutional rules'. This results in a space that is difficult to govern. Smith et al. (2013, p. 46) suggest that food in residential care for young people in Scotland is 'surrounded by official rules and regulations that prevent carers from making children a sandwich without having first completed a hygiene course'. In contrast, little evidence of this was found in the centres participating in this study, which went some way to dispelling the assumption that the kitchen would be one area of the 
centre where institutional regulations would overshadow the aim to provide a homely home.

\section{Regulation}

The purpose of residential care is to provide a safe, nurturing environment for children and young people who cannot live at home or with an alternative family for a period of time. Tusla, the Child and Family Agency (Tusla, 2015), recognises that returning a child to the family home or foster care is not always possible. As McHugh \& Meenan (2013) suggest, residential care can be the best option for some young people because living with a foster family could be a constant reminder of their own dysfunctional family home and may be associated with distressing situations. Residential care can be the preferred option for some young people. It can also be used to keep a sibling group together.

Residential care at present serves an increasingly marginalised population within the child-protection system and, according to Gilligan (2009, p. 15), 'the current function can be argued as serving as a "fall-back" to foster care'. According to Tusla, 'most young people are placed in residential care because their behaviour has become too challenging to be managed in any other care setting' (Tusla, 2015). This situation produces challenges for the young people living in the centres and for the workers employed there.

The National Standards for Children's Residential Centres (Department of Health and Children, 2001) are based on legislation, regulation and professional experience of what constitutes goodquality care, and they cover most aspects of children's everyday life in care. Under the provision of food and cooking facilities, the onus is on the centre and the workers to provide easy access to, and choice of, appetising and nutritious food, and encourage healthy eating habits. The resident group should also practise commensality. The standards are interpreted into tailored policy on how food should work in individual centres. Internal policy offers practical and nutritional guidelines and may include menu planning, the eating environment, factors that contribute to problematic eating, monitoring young people's nutritional status, food safety and hygiene. The workers further interpret the policy into the practicalities of feeding the young people in their care, themselves and their fellow workers while on duty. The external regulation and internal policies could represent 'the government of the table' (Coveney, 2008, p. 224). 


\section{Governance of the table}

Food plays a significant role in daily life for the young people and the workers in residential care (Emond et al., 2013; McIntosh et al., 2010; Punch et al., 2009). Food and eating practices are central to the creation of routine, rhythm and ritual in the centres. Food and eating practices are controlled by the workers in residential care centres for a range of reasons, including the supply, development and education of a healthy diet and eating habits. In addition, the workers are responsible for the safety and well-being of the residents with regard to food. The workers also have control over the access to certain food, such as treats, and to food spaces. On the other hand, young people can use food to try and gain control by choosing whether or not they eat the food, disrupting mealtimes and spoiling or wasting food, or they can earn a change of food routine through positive behaviour.

According to Coveney (2014, p. 64), where, what and with whom we eat are 'a matter of culture, governed by social mores, customs and traditions', and there are personal and political 'forces at play to shape and control our appetites'. Coveney (2006) employs the Foucauldian governmentality perspective to explore the problematisation of food and health. Governmentality was conceptualised by Foucault (1982) as 'the conduct of conduct'. Human conduct, according to Dean (2009, p. 17), 'is conceived as something that can be regulated, controlled, shaped and turned to specific ends'. Miller \& Rose (2008) argue that if governing implies the conduct of conduct, then there must be a problem with individual or collective conduct that needs conducting. They suggest that it makes sense to begin with questioning 'how this rendering of things as problematic occurred' (Miller \& Rose, 2008, p. 14), and demonstrate that problems are not pregiven; they are constructed through knowledge and made visible.

According to Coveney (2006, p. 12), a variety of methods have emerged through governmentality for knowing populations and for managing them through that knowledge. The everydayness of eating has become a problem, not just for the individual but also for society as a whole. The problems today include the need for self-control over our natural appetites and the apparent unlimited choice of foodstuffs available. Coveney shows that 'anxieties about our appetite for food have given and continue to give rise to concerns about the very moral fabric of society'. 
Concerns are usually couched in terms of our health, especially in terms of the scientific, calculated understanding of food we recognise as the field of nutrition. However, nutritional knowledge does not merely consist of facts, figures and recommendations from scientific experts. As a knowledge about what, when and how much to eat, nutrition provides a guide for individuals to assess their eating habits in terms of what is 'good'. (Coveney, 2006, p. xii)

Food has thus acquired a sense of morality. Through the knowledge of nutrition, we are required to become ethical, food-literate subjects with regard to what we should feed ourselves and the people we care for (Pike \& Kelly, 2014). Nutritional knowledge results in 'a powerful food morality that is both disciplined and disciplinary' (Coveney et al., 2012, p. 638).

A distinctive feature of governmentality is that it operates on selfregulation rather than passive submission. According to Foucault (1982, p. 790), 'power is exercised only over free subjects' because subjects are faced with a field of possibilities to which they can react in several ways. Due to the relatively recent recognition of children's rights, children have, to a degree, been provided with freedom of choice. Expert advice (Baker \& Henry, 1987; Stewart-Turner, 1986; Thompson, 1995) and state regulation for children in care (Department of Health and Children, 2001) dictate that children should be given choice and should participate in the decision-making about their diet. As a result, children are expected to be self-reflecting and self-regulating individuals, on the one hand, while on the other there is growing concern about what children choose to eat. This highlights a discursive tension between children's agency to act independently and adults' duty and responsibility for the socialisation and protection of children in their care.

Through governmentality, food spaces are also regulated. Expert advice on why we should eat at the table tells us that it is good for the body and the soul. Advice such as eating upright in a chair and eating in company aids digestion, prevents overconsumption and encourages children to eat more nutritious food. As for the soul, gathering at the table to eat creates a happy household. While we might know that not all family mealtimes live up to these claims, ethically we may feel guilt, at least some of the time, for not being able to achieve the ideal of the normal happy family gathered together daily to eat at the table. 
A residential care centre is a complex space where the spheres of private home and public work space overlap. As Peace \& Holland (2001, pp. 393-410) suggest, 'homely residential care' may be 'a contradiction in terms'. According to Ormond (2014, p. 258), there is an 'inescapable artificiality' in residential care centres. One young person in his study put it succinctly: 'How would you like to live in a house where people work?'

The overall aim of this research was to elicit the significance of food and eating practices in children's residential care settings in Ireland. Knowing how food is used in residential care - what is eaten, how, when and where - increases the sociological understanding of institutional eating practices in residential care for young people. Looking at the ordinary and everyday activities around the table can help to highlight how residential care works - an under-researched area in Ireland.

\section{Method}

The data are based on a series of empirical investigations collected as part of a PhD project, Around the Table: Food Work in Children's Residential Services in Ireland (Byrne, 2016). The project used an exploratory, sequential mixed-methods design. This article concentrates on the findings from the focused ethnography, which took place at the dining table in five residential care centres, the postal survey of ninety-two workers employed in residential care to examine the central role of food in residential care, and a review of twenty HIQA inspection reports for children's residential centres. The mixedmethods design allowed different but complementary data to be examined to address the research problem and explore the complexity of food and eating practices in daily life in the centres.

As this study involved research with a vulnerable population, access to a closed community and the private matter of food and eating, finding participants was challenging and the allotted time in the centres was limited. Focused ethnography was selected as it is considered less intrusive than other forms of ethnography and an effective method of working with this group. Focused ethnography is a methodological approach that, in contrast to conventional ethnography, is typified by short-term field visits and a preconceived research question by a researcher with insider or background knowledge of the cultural group. Focused ethnography does not attempt to study the entire social field but focuses on an individual 
part (Knoblauch, 2005). The kitchen/dining space in all the centres was a public area where the residents and workers drifted in and out. The method of data collection was a mix of audio recording and handwritten field notes of actions and conversations observed in and around the table. Situating myself in a public area went some way to addressing the child-protection issue of spending time alone with the young people. From the table, in all but one of the centres, the kitchen hotspots could be viewed - the kettle, the fridge, the dishwasher and the cooker - to note the action occurring. In all of the centres the workers sat at the table at mealtimes, and in the majority of cases the young people joined them at the table.

The managers acted as gatekeepers to the workers and the young people in the centres. The manager obtained initial permission from the resident group and their line manager in the HSE to carry out the research. Once the initial permission was granted, the first visit to the centre was arranged. The young people were asked for their assent/consent to take part in the research during this visit. At initial meetings with workers, discussions took place on the nature of what the research would include and reassurance was given that it was not an evaluation of their nutritional knowledge or cooking skills.

The survey was designed to further develop and clarify questions and issues that were identified during the focused ethnography. The survey covered several themes, including the basic profile of the food practices, emotions and feelings, power and resistance, food regulation and the workers' personal experience of food at work. This article concentrates on the regulation of food and eating practices in the centres, and the data from the observations and survey were supplemented by findings of a review of a selection of twenty HIQA inspection reports.

\section{Getting my feet under the table - Focused ethnography}

The five centres were very different, and located throughout Ireland. Three were mainstream, long-stay centres. One was a shortstay/respite centre and the other was a high-support facility. As Table 1 shows, the qualitative sample consisted of fifteen young people and sixty-three workers.

Young people living in residential care encounter many adults on a daily basis. The mainstream centres employed, on average, eight workers and a manager. Hillgrove, the high-support centre, had a considerably larger worker-to-young-person ratio. People from 


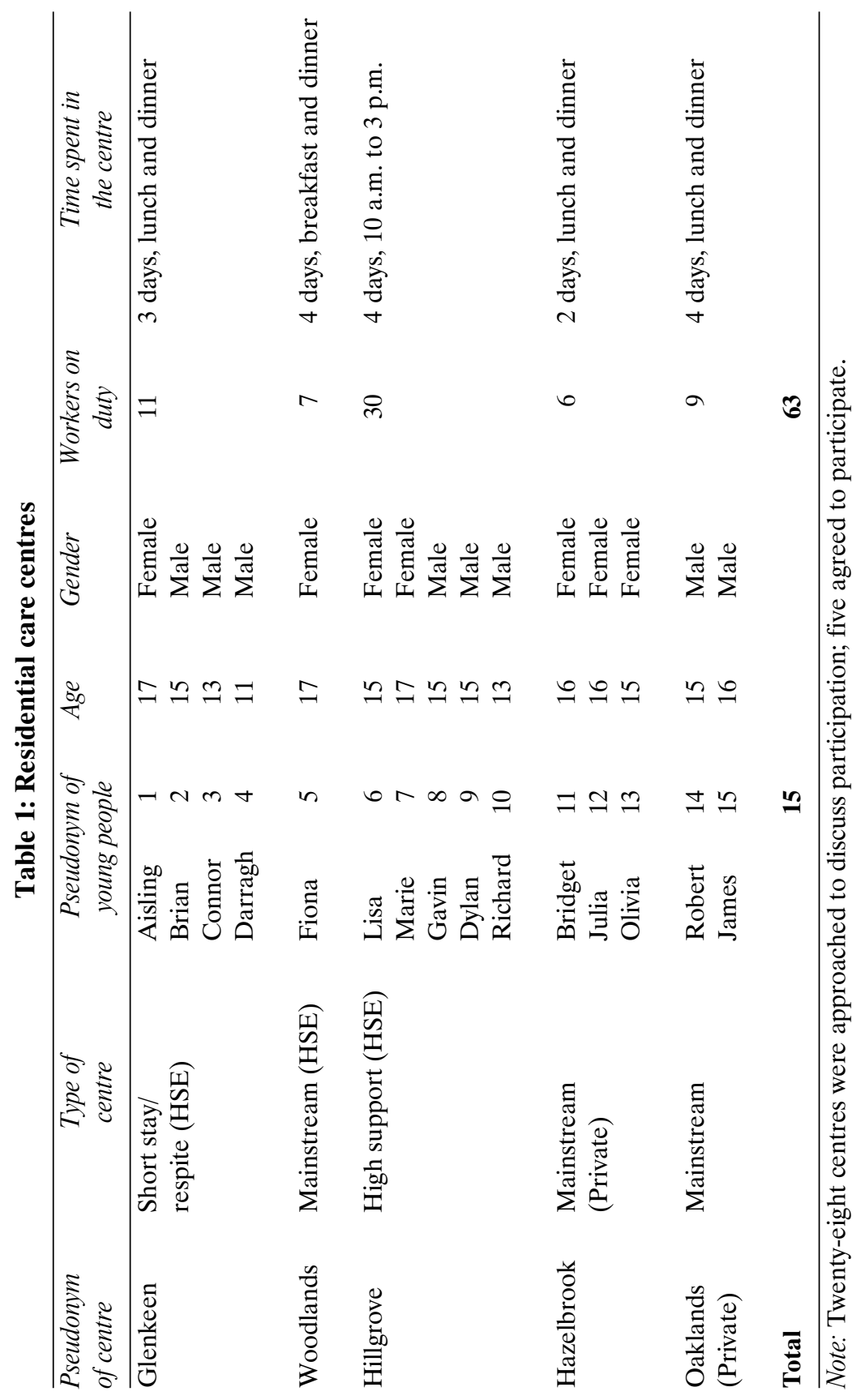


outside the centres also regularly visit and work with the young people. My presence would add to those encounters with adults. A residential care centre for young people is a hard-to-reach site. In this case my authorisation to be in the centre involved the following: the project had been approved by an ethics committee, Garda vetting had been completed, the young people and the workers had been informed that a researcher would be present, and the centre manager had decided when and for how long the research would last. This was not just someone 'dropping in' for dinner.

\section{External regulation}

The external regulations place the responsibility for the governance of the young people's food and eating practices on the workers in the centres. As discussed, the workers are required to supply the food and to encourage the development and education of the young people in healthy food and eating practices. The workers are also responsible for the safety and well-being of the resident group with regard to food. At the same time, the workers must govern their own food and eating practices within the centre to promote positive social gatherings at mealtimes and act as role models with regard to healthy eating.

The data collected from the observations and the workers' questionnaire provided the opportunity to gather information on how external regulation might impact on everyday life in the centres. There was an assumption that food and eating practices would be subject to high levels of regulation and that the Food Safety Authority of Ireland (FSAI) would have some authority in children's residential care. However, only the high-support centre, Hillgrove, was subject to inspections by the FSAI. The chef explained that the centre was inspected because a chef was employed there:

I have to keep reminding [the inspectors] that it is not a normal kitchen - it is the young people's home. You can't stop them from coming into their own kitchen. (Chef, Hillgrove)

The FSAI inspectors could not understand why the chef was unable to run the kitchen like any other industrial kitchen and keep records of temperature controls on the fridges. He described the young people coming into the kitchen, opening the fridge and just staring into it or leaving the fridge door open while they made themselves a sandwich. The image of a young person staring into the fridge looking for divine 
inspiration is an example of the conflict between home and institution. The chef's statement that this is not a 'normal kitchen' refers to the difficulty of balancing the strict regulation of the institutional kitchen with the more laissez-faire activities of a domestic kitchen. The fridgestaring incident was not witnessed during this research but it is assumed that the chef would inform the young people that leaving the fridge open increases the temperature inside and wastes energy. On the other hand, it is possible that the same conversation takes place in many domestic kitchens.

The other kitchens in this study were graded as domestic and therefore not subject to FSAI inspection. Non-domestic kitchens are obliged to have a food-safety management system in place, or a HACCP (Hazard Analysis Critical Control Point). This system requires food workers to be trained, and to control, monitor, record, and demonstrate compliance to safe food practices. If food work in residential care was subject to that level of external control, it would increase the institutional aspect of the centres.

The onus is placed on the workers in residential care to offer the young people a healthy and nutritious diet, but how do the workers acquire that nutritional knowledge? The results of the questionnaire show that four of the ninety-two workers had completed a food training course. Today workers do not receive training in food knowledge as part of their social care qualification, as they did in the past, and the sample here mainly rely on the information provided by food producers and discourses in the media to inform their food practices. Therefore, the construction of food knowledge appears, at present, to be an individual activity in residential care, as it is within the general public. Coveney (2006, p. 121) suggests that discourses on nutritional knowledge heighten ethical interest in our individual diets, that through self-regulation and self-reflection, healthy or unhealthy citizens are produced, and that 'the government of food choice' creates individuals who want to be healthy and 'experts instruct them how to be so'. Discussions with workers in the centres and results from the workers' questionnaire suggest the workers' source of food knowledge supports Coveney's theory on the penetration of nutritionist knowledge.

To promote confidence and inform the public, HIQA publishes the findings of its inspections online (see www.hiqa.ie). Reviewed here are the first twenty reports dating from October 2013 to June 2014 for reference to food and eating practices. The reports show that the standard for the provision of food and cooking facilities is not always 
reported. The inspectors did not comment on food and cooking facilities in half of those reports. The following statements reflect a selection of their comments on the centres inspected. The first statement is an inspector's conversation with a young person enquiring if standards are being met:

The young person at the unit told inspectors that they were happy with the food available and that their preferences are taken into account when planning menus. Inspectors found that there was fruit, snacks and drinks available to young people at all times.

The way in which the inspectors judged the food and references to them eating with the young people and workers were noted. The statement below shows that the inspectors do eat with the resident group during the inspection. There were also references to the atmosphere at the table, and generally the comments suggest that the mealtimes were positive social occasions:

Inspectors joined them for lunch on one of the days. The food was wholesome and nutritious.

The inspectors also reported on the monitoring of young people's food and eating practices and, as seen in the statement below, they also showed an interest in the workers' eating habits:

One unit manager told inspectors that she monitored staff to ensure that they role modelled healthy eating habits for the young people at the unit.

The HIQA inspection can be either announced or unannounced. After reading the statement below, I double-checked that this inspection had been unannounced:

The children told the inspector that they liked to cook, especially baking cakes, and the inspector saw the lovely cakes they baked for the staff team the evening prior to the inspection.

The workers and the young people are also aware the centre is governed by inspections, as illustrated by this recorded conversation from Oaklands: 
YP15: Are you here tomorrow?

Researcher: No, I am finishing up today (YP15 looked disappointed). It's a shame you've been out the past two nights as I have seen very little of you.

YP15: No, it's not that. We'll be back to dry bread tomorrow.

Manager: Don't worry. The inspectors will be coming soon. (Field notes, Oaklands)

Under the provision of food and cooking facilities, many of the reports agreed with the statement 'practice met required standard'. On the whole, references to food and cooking facilities were positive. The inspectors check that standards are being met, that a sufficient quantity of healthy and nutritious food is on offer, that mealtimes are positive social events and that young people are consulted on menu choice, and, if the young people are not consuming the healthy food on offer, they recommend that the workers monitor the situation. The sample of inspection reports reviewed indicates that food is not high on the inspectors' list of priorities. Further investigation into how the inspectors judge compliance with food and eating practices would be beneficial to understanding how the national standards are interpreted by HIQA inspectors.

\section{Internal regulation}

As discussed, internal food regulation and policy are based on the individual centres' interpretation of external regulation and expert knowledge. The centres' policies may offer practical guidelines on food safety and hygiene, nutritional menu planning, the eating environment, monitoring young people's nutritional status or factors that contribute to problematic eating. The individual workers further interpret those regulations and policies into the practicalities of feeding the young people in their care, their fellow workers and themselves.

\section{Access to food spaces}

The kitchen in any household is a potentially dangerous place. The possible hazards include burns and scalds from cookers and kettles, cuts from sharp objects, slipping on spills or the ingestion of hazardous chemicals. The kitchen is also the possible site for the contamination of food by bacteria. Food and eating spaces are also a flashpoint for 
conflict in residential care. No food-related conflict was witnessed, but this incident was described to me in Hazelbrook:

Bridget has wrecked the kitchen twice in the past five weeks. The second time the kitchen was destroyed and had to be redecorated. Every cupboard, drawer and the fridges were pulled out and the contents smashed. You would be amazed how far a jar of mayonnaise can spread. Everything in the kitchen was destroyed, except the Easter eggs and a large bottle of coke. (Manager, Hazelbrook)

In an attempt to ascertain how they controlled the situation, the manager was asked if they had locked the kitchen and she said:

No, our policy is not to lock rooms in the centre. (Manager, Hazelbrook)

The manager felt that, due to the inconvenience caused by the kitchen being out of use, Bridget would be more aware of the consequences of her actions in the future. On the other hand, the chef from Hillgrove, who by nature of his job had authority in the kitchen, did not let the young people's behaviour get out of control while he was in his kitchen:

Well, it is their home, but if they are getting too noisy or messing, they get put out. (Chef, Hillgrove)

Food-related conflict is referred to in the literature on residential care (Dorrer et al., 2011; Punch et al., 2009) with regard to control of access to food spaces. Dorrer et al. (2011, p. 29) discuss kitchens in residential care being locked 'at a time of difficult group dynamics' due to concerns for safety. To explore if this was a general policy, the workers in the survey were asked 'if food spaces in the centre were ever locked', and 30 per cent $(n=28)$ of respondents said yes. In one centre, one of the five responding workers said the kitchen was locked at night. Of interest here is that other workers from that centre did not recognise that the kitchen being locked at night restricted the young people's access. This was significant on many levels, not least that the young people's access to a glass of water was restricted.

The workers were asked if they thought that health and safety regulations could restrict the young people's cooking activities, and 
twenty-five agreed while five strongly agreed. In addition, seventy-five respondents said they did not have experience of health and safety regulations restricting young people's access to food spaces. However, this did not always refer to access to the kitchen. In some instances, they referred to knives being locked in cupboards. Of the fifteen workers who had experienced restricted access, six gave knives as an example, with reasons such as: 'not allowed in the kitchen when sharp knives are being used' (Worker 85) and 'they can't be up-skilled because they cannot use the knives' (Worker 72).

Young people's access to knives was made apparent during the pilot study. A young woman was peeling potatoes with a table knife and when asked if there was a paring knife, she said 'it's not worth the trouble'. If a young person in this centre wanted to use a sharp knife, they had to ask a member of staff to get the knife for them, a worker had to be free to supervise the young person while using the knife and, when they had finished, the knife was locked away again. In all the centres visited, the knives were kept under lock and key, with the possibility of a young person self-harming being given as the reason. In Glenkeen, Oaklands and Woodlands the knives were kept locked in the office. In Hazelbrook the knives were kept in a safe inside a locked cupboard in the kitchen. On my first day in Hazelbrook, Kelly (Worker 52) was in the kitchen preparing bolognese sauce for the dinner and, in a discussion about the safe, she said:

The joke is we don't even have a sharp knife. (Worker 52, Hazelbrook)

The workers also have to be vigilant when using knives while preparing meals. When discussing this with one group of workers, there was consensus that they only took the knives out if it was absolutely necessary. The workers have to read the situation carefully because sometimes it is safer not to add knives to an unstable situation.

This research began with the assumption that the kitchen would be one area of the centre were institutional regulations would outweigh the aim to provide a homely home. McIntosh et al. (2010, p. 294) found that the kitchen in residential care 'was subject to a panoply of health and safety regulation and elevated levels of supervision and surveillance'. There was an expectation that posters or signage on food hygiene, hand-washing or food storage would be evident. Visual signs of institutional regulations were noted upon first entering the centres' kitchen/dining rooms. In the mainstream centres there was very little 
evidence of regulatory signage. Figure 1 shows signs above the sink of the utility room in Hillgrove. The dishwasher was situated beside this sink and the young people must have been in the habit of scrapping their plates into the sink. The member of staff who put up these signs was obviously tired with cleaning up the mess. However, the worker appears to be trying to soften the message by scalloping the edges of the notices.

Figure 1: The height of laziness

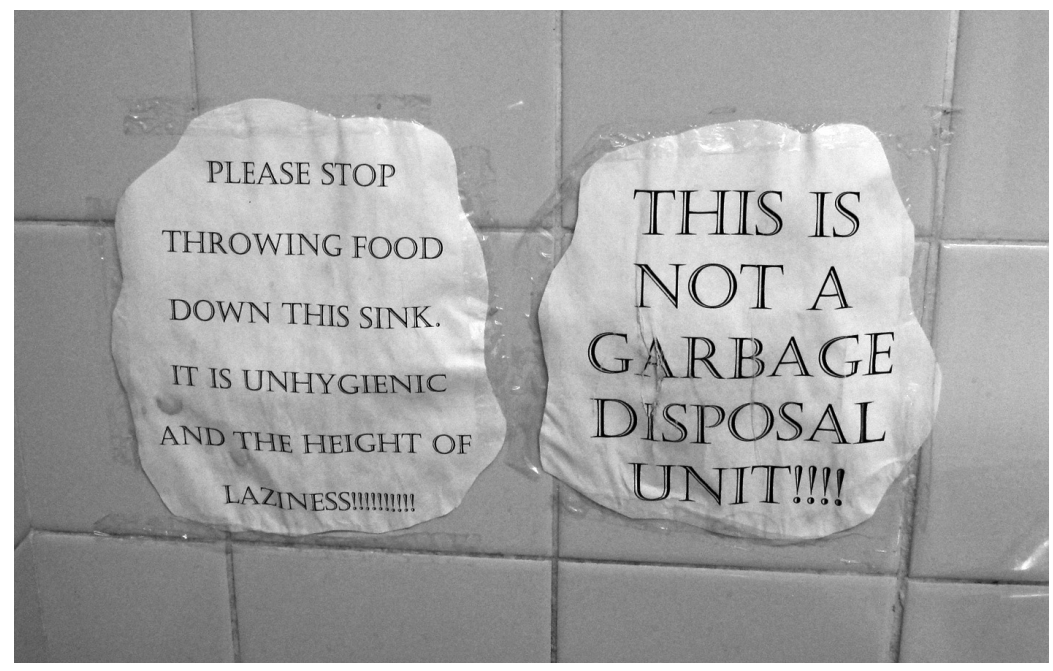

The worker is dealing with negative behaviour that needs to be controlled. Workers, according to McIntosh et al. (2010), would prefer to emphasise their caring role. The softening of the edge of the message could thus perhaps be viewed as a symbolic representation of the ambivalence experienced by workers having to exercise control over young people. The following discussion on young people's involvement in food-related chores was recorded in Glenkeen. The young people had left the table and one worker had started to tidy the kitchen:

Worker 7: [Worker 6] come and sit a while. (She had started to tidy the kitchen.)

Worker 6: Who didn't clear their plate?

YP4 \& YP2: Connor [YP3].

Worker 7: He's terrible at that. 
Worker 6: Yes. We would encourage the kids to help but we've got a bit slack with it - to help with the cooking and setting the table and stuff but that kind of goes by the wayside after a while, but the one thing we always hold on to is clearing their plates, but you don't want to be at them when they're just in the door from school. (Field notes, Glenkeen)

\section{Eating at the table}

Eating together at the table, or commensality, is encouraged by the workers and is stipulated in the National Standards for Children's Residential Centres (Department of Health and Children, 2001). This study showed that 96 per cent $(n=88)$ of the workers believed that the young people should be encouraged to eat at the table. In response to the statement 'Young people should be able to eat where and when they like', 11 per cent $(n=10)$ of workers agreed. Therefore, it can be assumed, through subtle or overt disciplinary codes, that the young people are directed towards the table. Another reason for sharing meals at the table is to monitor what the young people are eating and 88 per cent $(n=81)$ of the respondents agreed that monitoring the food young people eat improves their dietary intake. A further 72 per cent $(n=67)$ agreed that young people eating at the table consume more nutritious meals, suggesting that if young people are not watched over, they are at risk of making unhealthy food choices.

As discussed, commensality is a highly regarded aspiration in residential care, as it is more broadly in society, and 93 per cent $(n=86)$ of the workers agreed with the statement 'The group eating together at the table is an opportunity to create a "homely" feel in the centre.' The table in residential care plays an important role in creating and maintaining the routines, rhythm and rituals of everyday life (Smith et al., 2013). The shared meal at the table is predictable it can create a sense of ritual and normality. According to Storø (2013, p. 130), rituals can represent 'the security of the constant recurring'. The shared meal with the resident group requires little reflection - it is just the way things are done. Sharing food at the table offers a point of consistency. Through repetition, using the dining table becomes a cultural norm to which the workers and the young people become accustomed. Eating together at a dining table may be unfamiliar for some young people entering care and they may resist joining the group at the table (Punch \& McIntosh, 2014). Workers, because of their hierarchical elevated position, both as adults and professionals, may 
find ways to avoid eating with the residential group at the table. Due to the young people's position in the hierarchy, they may not have the same freedom.

The National Standards (Department of Health and Children, 2001) require that meals be regarded as positive social events, and the findings of this research show that 80 per cent $(n=74)$ of workers regard mealtimes as social time, and not work time. Residential care workers' meal breaks are taken with the children and young people, so mealtimes are not a 'break' as they would be for the majority of workers in other occupations. Sitting at the dining table for residential care workers entails eating the same food as the residents, being a positive role model around food, encouraging good table manners and being social. Sharing meals with clients is not expected of the workers in the majority of 24-hour care facilities; for example, residential care for older people or hospitals. Recognition of the social aspect of working in the young people's living space is a particular feature of social care practice and is, for some social care practitioners, the key element of their work in Ireland. Lalor \& Share (2013) suggest that it is the ordinary and informal activities of everyday life that provide opportunities for relationships to be developed between the workers and the young people. The shared meal may be considered as a 'rhythmic interaction that becomes apparent when children and adults share moments and move ahead together' (Maier, 1979, p. 6).

The literature suggests that there is a preconceived idea that the residential environment 'teeters on the brink of a loss of control' (Smith, 2009, p. 95). Prior to commencing fieldwork, there was doubt that the idealised image of the positive social group sitting around the table, eating the same food and having interesting conversations, would be observed in reality. Several mealtimes observed in the field were not dissimilar to the idealised image. There were also mealtimes where another image of family life was evident - that of complaints about the food from the young people. These mealtimes were not fraught with tension; rather they were reminiscent of regular ebb and flow of family life. This was an unexpected finding as encounters between the workers and the young people are shaped within the framework of unequal power relations, and the dining table - as with family dining tables in general (Wilk, 2010, p. 429) - is a setting where the inequities of power based on gender and age can be played out. It may be that the harmonious mealtimes witnessed were an example of the ritual of the shared meal in residential care providing 'an order out of disorder' (Emond et al., 2013, p. 7). 
My time spent in the centres indicates that the workers must navigate their way through regulation, policy, health campaigns, nutritional advice and discourses of risk to produce their own ideas of 'proper food' and 'proper manners' for the young people in their care, their fellow workers and themselves - 'to conduct the conducts of others and the self' (Huxley, 2008, p. 1,641). The observational data showed that, apart from in Hillgrove, the young people did eat at the table with the workers. According to McIntosh et al. (2010) and Punch et al. (2009), young people can feel vulnerable at the table because they are monitored and assessed by not just the workers but also their fellow residents. The group dynamic in Hillgrove was described as unstable as it was a new resident group. After the first lunch, the workers were asked about the boys not eating at the table. The following is an extract from the field notes:

Worker 43: They would rather spend their free time playing on the Xbox in their rooms than eating.

Worker 41: You know some young people don't want to eat at the table because they do not want to sit with the staff or eat in front of other people that they don't know.

Researcher: Are they allowed to eat in their rooms?

Worker 43: Of course, they can eat were they like.

Researcher: How do you get them to come to the table?

Worker 41: You just have to give them time. You keep asking them but do not make a big deal of it. Some young people are not used to eating proper meals but, given time, they usually come to the table and you can see them physically thrive. (Field notes, Hillgrove)

The workers are expected to steer the young people in the direction of developing good eating practices at the table so they can in turn become healthy, socially skilled citizens. This study has shown that the majority of workers thought that young people should be encouraged to eat at the table because they will make healthier food choices there. However, conducting the conduct of others is not always straightforward, as the workers' ideas of food conduct can be challenged by the young people. As this worker from Oaklands points out, 'Most of the young people coming into care are sixteen or seventeen. How can you change their eating habits?' (Worker 57). 


\section{Three square meals}

All the centres provided three meals a day: breakfast, lunch and dinner. The workers in all the centres said that the young people had access to the kitchens and could help themselves to snacks or cook themselves a meal. The time of the evening meal was flexible and depended on who was doing the cooking. Woodlands appeared to have the least flexible attitude to mealtimes, and it was in this centre that most conflict was recorded (as the quote below indicates).

It's horrible here - they cook dinner but I don't eat it. (YP5, Woodlands)

Punch et al. (2009) suggest that food can be used as a safe way to test boundaries. It may be easier for a young person living in care to say that they hate the food rather than the worker who offers it. Food can also be used to reject care or to demonstrate power. This was illustrated by Fiona (YP5), who would not eat the food prepared by the workers and preferred to cook her own food. The conversation below was recorded when we first met:

YP5: It's horrible.You'll hate it.

Researcher: The place or the food.

YP5: Both. (Field notes, Woodlands)

Section 6.9 of the National Standards (Department of Health and Children, 2001) requires that the young people should have an input into menu planning. The survey asked how often the young people are consulted about menu choice. Fifty-four respondents said weekly and thirty-one said daily. Of the remaining seven respondents, six were from the centre that employed a chef and their responses ranged from 'rarely' to 'never consulted'. The chef in this centre prepared set meals from a four-week rolling menu. Punch et al. $(2009$, p. 17) found that the workers and young people disliked the repetitive menu, and that the cook may represent 'the institutional dimension of the home'. On the other hand, for some young people and workers, it could be an example of the 'security of the constant recurring' (Storø, 2013, p. 130).

This research hoped to elicit how the regulation to provide a healthy diet was interpreted and how food choice was managed. The What Ireland Ate Last Night study, carried out by Bord Bia, found that the 'proper dinner' consisting of meat and two vegetables was Ireland's 
favourite style of dinner and that spaghetti bolognese was the favourite dinner for children (Bord Bia, 2011). It was evident from the residential centres visited in the present study that 'traditional Irish dinners', or a 'proper dinner', were not being served.

In here, some kids' idea of a Sunday dinner is pizza and chips. (Worker 16, Woodlands)

The comment from this worker suggests that children coming into care are not familiar with the idealised proper dinner. The workers in this study were asked to list the three most frequently cooked dinners in the centre and variations on the 'proper dinner' was the most frequent, with 'roast' being referred to most often. No 'proper dinners' were cooked during the visits conducted as part of the observational element of this study, all of which were conducted midweek. A roast dinner is revered as an institution in its own right and may be the highpoint of the weekly menu, and therefore was easily recalled to memory for the workers. The second most frequently recalled meal was described as varying types of pasta, followed by curry. This corresponds with the data obtained through the focused ethnography, as the most frequently cooked meals were pasta dishes.

The workers are responsible for offering healthy food choices but they cannot determine if the young people will eat what is offered. In the current climate there is a concern that children's health is at risk because of the food choices being made by them and on their behalf. It could be argued that children in the care of the state should be eating the diet recommended by the state authorities. The ideal diet, according to Safefood (2014), comprises enough starchy wholegrain foods to meet your energy needs, lots of fruit and vegetables, some dairy, some protein and little or no energy-dense and salted foods. The meals viewed in this research contained no wholegrain and very little fruit and vegetables. The meals offered were similar to the diet reported by Bord Bia (2011), and the reported alternatives eaten by the young people consisted mainly of sandwiches or noodles. Children living in residential care in the past were strongly encouraged and, in some instances, as the reports from the Commission to Inquire into Child Abuse (2009) show, forced to eat food they disliked. Workers who have to struggle to get young people to eat a healthy diet can lose sight of the bigger picture: where eating is 'a pleasurable experience and food consumption an enjoyable social ritual' (Smith et al., 2013, p. 46). This points to one of the key policy/practice issues: a centre may 
have a healthy eating policy but what are the workers to do in practice when a young person will only eat Pot Noodle? These days, the desire to avoid a young person going hungry will most likely determine the outcome.

\section{Conclusion}

This paper has drawn on 'the government of the table' (Coveney, 2008, pp. 224-43) to explore how food and eating practices are governed in residential care for young people in Ireland. As argued at the beginning, food is central to our everyday lives but its significance can often be overlooked. Food is a powerful tool in residential care and can help to make young people feel welcome and cared for. It can also help the workers to fulfil their caring duty by providing food for the children in their care.

From the data collected during the focused ethnography, the workers' survey and the review of HIQA inspection reports, it was evident that commensality is highly regarded and practised in children's residential care. The resident group regularly sit at the dining table and share the same food. The workers felt that this social aspect of the mealtime was an opportunity to create a homely feel in the centre, and the majority of workers believed that the young people should be encouraged to eat at the table and that, by so doing, they would consume more nutritious meals. This study has found that, at the majority of observed mealtimes, young people chose to be at the table with the workers. The young people lingered in and around the table after the meal had ended; they were not fraught affairs. The workers from the survey regarded mealtimes as social time as opposed to work time - this could indicate that mealtimes are, more often than not, positive events.

In the majority of the centres participating in this study the kitchens were graded as domestic. A domestic kitchen is not controlled by outside authorities. Therefore, it is self-regulated and responsibility appears to lie mainly with the individual workers to inform themselves about food safety and nutrition. The findings suggest that the young people and the workers' food and eating practices carried out in these domestic kitchens help in the creation of a homely feel in the centres.

In policy and practice there are established tensions between domestic and institutional living. Peace \& Holland (2001) suggest that those tensions may be insurmountable. However, one aspect of the workers' job is to help the young people in their care to feel at home. 
Workers rarely have any involvement with the design or building of residential care centres (Maier, 1979). They are, more often than not, challenged with how best to adapt the present setting to fit with their interpretation of a homely environment. The young people, when they arrive in the centre, have to construct a sense of home despite having no deep connection with it or how they should behave there. This study has found that food is an important instrument to demonstrate and practise homely activities in the centres. Food is commonly associated with ordinary routines of everyday life. Food and eating practices help to create routines, rhythms and rituals in the centres. Food and eating practices offer a point of consistency and a sense of security and predictability; they require little reflection - that is just the way things are done. Relationships between workers and the young people are created and recreated by those everyday routines, rhythms and rituals. Relationships are central to contemporary residential care practice, and food plays a significant role in the building of relationships between the workers and the young people.

\section{References}

Baker, S., \& Henry, R. (1987). Parents' guide to nutrition: Healthy eating from birth through adolescence. Massachusetts: Addison-Wesley.

Bell, D., \& Valentine, G. (1997). Consuming geographies: We are where we eat. Oxon: Routledge.

Bord Bia. (2011). What Ireland ate last night: A study of last night's evening meal. Dublin: Bord Bia.

Byrne, D. (2016). Around the table: Food work in children's residential services in Ireland. Unpublished $\mathrm{PhD}$ thesis, Institute of Technology Sligo.

Clark, A., Cameron, C., \& Kleipoedszus, S. (2014). Sense of place in children's residential care homes: Perceptions of home? Scottish Journal of Residential Child Care, 13 (2), 1-18.

Commission to Inquire into Child Abuse. (2009). Commission to Inquire into Child Abuse. Volumes 1-5. Dublin: Commission to Inquire into Child Abuse. Coveney, J. (2006). Food, morals and meaning: The pleasure and anxiety of eating (2nd ed.). London: Routledge.

Coveney, J. (2008). The government of the table: Nutrition expertise and the social organisation of family food habits. In J. Germov \& L. Williams (Eds), A sociology of food and nutrition: The social appetite (3rd ed.) (pp. 224-43). Australia: Oxford University Press.

Coveney, J. (2014). Food. Oxon: Routledge.

Coveney, J., Begley, A., \& Gallegos, D. (2012). 'Savoir Fare': Are cooking skills a new morality? Australian Journal of Adult Learning, 52 (3), 618-42. 
Dean, M. (2009). Governmentality: Power and rule in modern society (2nd ed.). London: Sage.

Department of Health and Children. (2001). The national standards for children's residential centres. Dublin: The Stationery Office.

Dorrer, N., McIntosh, I., Punch, S., \& Emond, R. (2011). Children and food practices in residential care: Ambivalence in the 'institutional' home. In S. Punch, I. McIntosh \& and R. Emond (Eds), Children's food practices in families and institutions (pp. 21-34). London: Routledge.

Emond, R., McIntosh, I., \& Punch, S. (2013) Children, food and care IRISS insights, no 22. Retrieved from www.iriss.org.uk/resources/children-foodand-care [8 October 2015].

Foucault, M. (1982). The subject and power. Critical Inquiry, 8 (4), 777-95.

Gilligan, R. (2009). Residential care in Ireland. In M. E. Courtney \& D. Iwaniac (Eds), Residential care of children: Comparative perspectives ( $\mathrm{pp}$. 3-19). Oxford: Oxford University Press.

Huxley, M. (2008). Space and government: Governmentality and geography. Geography Compass, 2/5 (2008), 1,635-58.

Knoblauch, H. (2005). Focused ethnography. Retrieved from www.qualitativeresearch.net/index.php/fqs/article/view/20 [19 September 2015].

Lalor, K., \& Share, P. (2013) Applied social care: An introduction for students in Ireland (3rd ed.). Dublin: Gill \& Macmillan.

Maier, H. (1979). The core of care: Essential ingredients for the development of children at home and away from home. Child Care Quarterly, 8 (3), 161-73.

McHugh, J., \& Meenan, D. (2013). Residential child care. In K. Lalor \& P. Share (Eds), Applied social care (3rd ed.) (pp. 243-58). Dublin: Gill \& Macmillan.

McIntosh, I., Punch, S., Dorrer, N., \& Emond, R. (2010). 'You don't have to be watched to make your toast': Surveillance and food practices within residential care for young people. Surveillance and Society, 7 (3/4), 290-303.

Miller, P., \& Rose, N. (2008). Governing the present. Cambridge: Polity Press.

Ormond, P. (2014). Thought on the good enough worker. In N. Howard \& D. Lyons (Eds), Social care: Learning from practice (pp. 241-6). Dublin: Gill and Macmillan.

Peace, S., \& Holland, C. (2001). Homely residential care: A contradiction in terms? Journal of Social Policy, 30 (3), 393-410.

Pike, J., \& Kelly, P. (2014). The moral geographies of children, young people and food: Beyond Jamie's school dinners. London: Palgrave MacMillan.

Punch, S., \& McIntosh, I. (2014). Food is a funny thing within residential care: Intergenerational relationships and food practices in residential care. Childhood, 21 (1), 72-86.

Punch, S., McIntosh, I., Emond, R., \& Dorrer, N. (2009). Food and relationships: Children's experiences in residential care. In A. James, A. T. Kjorholt \& V. Tingstad (Eds), Children, food and identity in everyday life (pp. 149-71). Basingstoke: Palgrave MacMillan. 
Safefood. (2011). Body weight and eating habits in 5-12 year old Irish children: The national children's food survey summary report. Dublin: Safefood.

Safefood. (2014). Guide to healthy eating. Retrieved from http://www.safefood.eu/SafeFood/media/SafeFoodLibrary/Documents/Co nsumer/Healthy\%20Living/Guide-to-Healthy-Eating-pdf-Booklet.pdf [18 July 2016].

Smith, M. (2009). Rethinking residential child care: Positive perspectives. Bristol: Policy Press.

Smith, M., Fulcher, L., \& Doran, P. (2013). Residential care in practice: Making a difference. Bristol: Policy Press.

Stewart-Turner, A. (1986). The complete guide to feeding your child. Australia: Science Press.

Storø, J. (2013). Practical social pedagogy: Theories, values and tools for working with children and young people. Bristol: Policy Press.

Thompson, S. (1995). A healthy start for kids: Building good eating patterns for life. Sydney: Simon \& Schuster.

Tusla. (2015). Alternative care. Retrieved from www.tusla.ie/services/ alternative-care [15 November 2015].

Wilk, R. (2010). Power at the table: Food fights and happy meals. Cultural Studies - Critical Methodologies, 10, 428-36.

Wright, J., Burrows, L., \& Rich, E. (2012). Health imperatives in primary schools across three countries: Intersections of class, culture and subjectivity. Discourse: Studies in the Cultural Politics of Education, 33 (5), 673-92. 